\title{
A iniciação docente em Educação Física: um estudo com egressos do programa PIBID/UNEB Campus XII
}

\begin{abstract}
Resumo: O presente trabalho busca compreender como os fatores relacionados ao Programa Institucional de Bolsa de Iniciação à Docência (Pibid), desenvolvido na Universidade do Estado da Bahia (UNEB) Campus XII, incidem sobre a prática docente dos professores em início de carreira. O objetivo é averiguar as contribuições do Pibid para a definição da trajetória profissional docente, a fim de relatar reflexões sobre a permanência do professor de Educação Física no contexto escolar da rede pública de ensino. Para tanto, foram entrevistados 10 egressos do curso de Educação Física que fizeram parte do programa Pibid/UNEB como bolsistas de Iniciação à Docência. O público alvo da pesquisa foram os professores nos primeiros anos da experiência docente. Através da análise dos dados, foi possível perceber que o Pibid, qualifica a formação inicial dos futuros professores de Educação Física, estimulando a permanência do licenciado no exercício da carreira. Assim, nas falas dos egressos, o Pibid é visto com fundamental importância para a formação docente dos acadêmicos que nele estão inseridos. E que através de suas articulações, o programa se torna imprescindível para aquele que deseja se preparar para ingressar profissionalmente no espaço escolar. Enfim, por meio de todo o estudo realizado e das sugestões pedagógicas apresentadas foi possível refletir sobre a influência que o Pibid tem na qualificação da formação e início da atuação docente. Sob essa perspectiva, o Programacumpre um importante papel na constituição do repertório de conhecimentos, crenças e fazeres necessários à atuação profissional docente.
\end{abstract}

Palavras-Chave: Pibid. Formação Docente. Atuação profissional. Educação Física.

\section{Introdução}

A construção de alicerces teóricos para a Educação Física é um empreendimento coletivo e de grande esforço, especialmente quando as dificuldades têm se avolumado sob o peso da paralisação, quase generalizada, das ações em relação à área. (TAFFAREL; ESCOBAR, 2007) A produção científica na Educação Física traz problemáticas no âmbito de sua organização com o trabalho pedagógico e no trato com o conhecimento, distancia-se de um perfil de produção acadêmica atrelada a uma formação e atuação crítica. Dessa forma, a reestruturação do campo teórico estabelece necessidades de ajustes nos campos profissionais que se expressam em uma organização da produção científica que propõe um diálogo estreito com os profissionais em ação. Contudo, as discussões acadêmicas na área da Educação Física tiveram um avanço significativo nas
Marlon Messias Santana Cruz - UNEB

marlonmessias@hotmail.com Lidiany Ferrera Lisboa liddylisboa@hotmail.com 
últimas três décadas. Suas intervenções pedagógicas, no entanto, ainda são fortemente marcadas por uma visão predominantemente biológica. Uma das consequências produzidas por essa visão é a compreensão da Educação Física como um componente curricular que trata do corpo e do movimento em seu sentido estritamente orgânico e funcional, e não do homem nas suas manifestações culturais relacionadas ao movimento. (OLIVEIRA; CRUZ, 2016) Essa compreensão é ainda corroborada pela dicotomia entre educação intelectual e educação corporal e pela ideia culturalmente cristalizada de superioridade do intelecto sobre o corpo, que foram criadas pela racionalidade ocidental moderna. (BRACHT, 1999) Todos esses elementos têm contribuído para uma segregação da Educação Física no currículo escolar, pois, conquanto a atual legislação educacional brasileira a tenha definido como "componente curricular obrigatório da educação básica". (BRASIL, 1996), ela continua sendo vista como uma atividade à parte, complementar ao currículo, desvalorizada perante os demais componentes, sem o reconhecimento de seus objetivos educacionais próprios.

O presente trabalho busca apresentar como as atividades relacionadas ao Programa Institucional de Bolsa de Iniciação à Docência (Pibid), desenvolvido no curso de Licenciatura em Educação Física na Universidade do Estado da Bahia (UNEB) Campus XII, incidem sobre a formação profissional docente dos bolsistas de iniciação à docência, a fim de relatar reflexões sobre o início da carreira docente dos professores egressos do Pibid, e como as ações desenvolvidas no programa contribuem para a efetiva prática pedagógica destes professores.

O Pibid, proposto e financiado pela Coordenação de Aperfeiçoamento de Pessoal de Nível Superior (Capes), é uma iniciativa política que se configura na atual conjuntura educacional, marcada por diversos problemas e dificuldades, entre os quais se destaca a necessidade de melhoria da qualidade do ensino público e da formação de professores. (OLIVEIRA; CRUZ, 2016) Diante desse quadro, o programa se baseia no reconhecimento da escola enquanto o lócus dos processos de formação docente (MARCELO, 2009), reconhecendo também a importância da parceria entre as instituições de Ensino Superior e de Educação Básica na condução desses processos. Seu principal objetivo, portanto, é promover a inserção dos estudantes de cursos de licenciatura - bolsistas de iniciação à docência - no cotidiano das escolas públicas, desde 
o início da sua formação acadêmica, para que eles desenvolvam ações concretas nesse contexto, sob a orientação de um docente do curso (coordenador de área) e de um professor da escola (bolsista de supervisão).

O Pibid se efetiva por meio de projetos submetidos à Capes por Instituições de Ensino Superior que possuem cursos de licenciatura. Esses projetos institucionais, por sua vez, são compostos por diferentes subprojetos, cada um deles desenvolvido por um curso de licenciatura.

Diante desse quadro, o subprojeto desenvolvido no curso de Educação Física da UNEB - Campus XII, além de inserir o estudante de licenciatura na realidade das aulas de Educação Física na escola pública, busca também contribuir para a legitimação da Educação Física na escola, a partir da construção coletiva de uma prática pedagógica orientada por princípios democráticos e de valorização da diversidade. (OLIVEIRA; CRUZ, 2016)

Para alcançar tais propósitos, suas ações do subprojeto fundamentam-se teoricamente na perspectiva Cultural da Educação Física, bem como, no Multiculturalismo Crítico, pois para essa perspectiva, não há conhecimentos considerados mais ou menos legítimos, adequados ou inadequados, válidos ou não válidos. Isso significa que todas as formas de manifestação e expressão corporal devem ter espaço nas aulas de Educação Física na escola, uma vez que a validação de certos conhecimentos em detrimento de outros contribui para a legitimação de determinados interesses e para a constituição da identidade dos sujeitos que frequentam a escola. (OLIVEIRA; CRUZ, 2016)

Portanto, o objetivo do trabalho é averiguar as contribuições do Pibid para a definição da trajetória profissional docente, a fim de relatar reflexões sobre a permanência do professor de Educação Física no contexto escolar da rede pública de ensino.

Para isso, o delineamento metodológico do estudo versa sobre a abordagem qualitativa de pesquisa, o contexto da investigação perpassa pela pesquisa de campo, ou seja, trata-se de uma pesquisa qualitativa em que a maior preocupação é compreender um grupo social, organização, instituição ou trajetória do assunto pesquisado. (GOLDENBERG; RAMOS 2002) Busca-se compreender o que define a trajetória dos egressos do curso de licenciatura, objeto da pesquisa, para assim, refletir sobre a carreira profissional docente 
destes egressos, os resultados da pesquisa foram discutidos a partir da análise de conteúdo.

A pesquisa foi realizada com 10 egressos do programa Pibid/ UNEB, do curso de Licenciatura em Educação Física - Campus XII da cidade de Guanambi-Ba, professores formados nos últimos cinco anos. Os professores entrevistados atuam em escolas públicas, estaduais e municipais, localizadas na microrregião do município de Guanambi, estado da Bahia, e que atuaram como bolsistas de iniciação à docência. Para a coleta dos dados foi utilizada a entrevista semiestruturada, gravadas por um gravador de voz e transcritas para fins de análise. Foram utilizados nomes fictícios para preservar a identidade dos participantes da pesquisa. Foram encaminhados convites para 25 egressos do programa Pibid/UNEB, porém só 10 professores retornaram o convite e aceitaram contribuir com a pesquisa.

As entrevistas foram realizadas conforme disponibilidade e indicação dos locais pelos participantes, os encontros aconteceram nas escolas que os professores trabalham e nas dependências da UNEB Campus XII, município de Guanambi. O roteiro das entrevistas tratou inicialmente de identificar o campo de atuação do(a) professor(a), e o tempo efetivo de atuação na educação básica. Posteriormente, os questionamentos versavam sobre as possibilidades do trabalho docente na educação básica, bem como as contribuições do Pibid para sua atual prática docente. Para encerar, a entrevista tratou de identificar com o Pibid desenvolveu nos professores(as) o interesse e desejo em permanecer com professor(a) da Educação Básica.

\section{O Pibid e a formação da identidade docente}

A reflexão sobre a formação docente, sua possibilidade de mudança e inovação, é apropriada para o atual momento sociopolítico do Brasil. É oportuno tecer considerações sobre a atual conjuntura social e seus reflexos na formação e atuação docente. O avanço do neoliberalismo nas políticas econômicas do país culmina com a negação de direitos historicamente conquistados no campo social. A educação é um destes direitos, e isto reflete na formação do professor, pois esta sofre ataques em seu fazer e pensar metodológico e didático. Portanto, de acordo com Rosa e demais autores (2008, p. 26), "[...] a identidade profissional docente está atravessada por 
discursos oriundos de campos em disputa, o que deriva das noções de identidades múltiplas ou fragmentadas".

Fica ainda mais clara a impossibilidade de quebra do elo entre a universidade e a escola para a formação do professor. Ambas têm papel fundamental e juntas preparam um profissional competente, onde a concepção de competência mais difundida é composta por três dimensões básicas: conhecimentos, habilidades e atitudes. No entanto, não se pode atribuir separadamente o domínio do conhecimento à universidade, o de habilidades específicas, às escolas e o relativo às atitudes ficar ao encargo do aluno e futuro professor. Todas as agências formadoras são responsáveis pelas três dimensões ao mesmo tempo. (LUDKE; BOING, 2012)

É com base nesse contexto que deve ser direcionada a formação em licenciatura: a vivência teórica unida com a reflexão sobre a prática exercida para basear as atitudes corretas da profissão. A cargo da universidade fica também a responsabilidade de proporcionar essas práticas o quanto antes após a entrada do aluno na graduação. Tal fato se apresenta como maneira plena para formação do professor, além de levar o licenciando a conhecer e refletir sobre sua futura profissão, podendo decidir precocemente se é realmente o que ele deseja e evitar frustações ao término do curso.

Não existe formação em licenciatura sem a prática docente. É preciso alcançar um equilíbrio entre a discussão e a atuação desde o início da graduação. Nóvoa (2009) argumenta sobre a necessidade de uma formação construída dentro da profissão, instituindo as práticas profissionais como lugar reflexivo e formativo. Impondo a inversão da tradição que domina a formação de professores por meio de referências externas do que por referências internas ao trabalho docente. Apesar de hoje ainda não ser uma prática tão constante nos cursos de licenciaturas, percebe-se a necessidade de inserção do futuro professor no âmbito profissional a partir do ingresso na universidade, de modo que a teoria e a prática caminhem juntas, dando origem à construção concreta de um conhecimento profissional docente.

Ainda em Nóvoa (2009) é ressaltada a importância de conceber a formação num contexto de responsabilidade profissional, na qual ele sugere uma atenção constante à necessidade de mudanças nas rotinas de trabalho: pessoais, coletivas ou organizacionais. De modo que a inovação é um elemento central do processo de formação. A vivência prévia da realidade da profissão se apresenta para o alu- 
no como oportunidade de conhecer ao que ele será destinado no futuro, além de compreender as dificuldades que estão presentes nesse ofício docente. É importante que não haja acomodação em meio aos obstáculos que surgirão na carreira do professor, é nesse momento que nasce a necessidade de inovação e superação para que o objetivo seja alcançado.

O Pibid no Curso de Licenciatura em Educação Física, no Campus XII da UNEB, iniciou em 2012 com 10 bolsistas de Iniciação à Docência (estudantes da licenciatura), duas bolsistas de Supervisão (professoras da Educação Básica) e uma bolsista de coordenação (coordenadora de área, professora do ensino superior), em 2014 houve uma ampliação no número de bolsistas, por meio de um novo edital. Ainda sobre o histórico do Pibid no curso, em 2018 houve um novo edital da Capes, o qual reestruturou as concepções de desenvolvimento do subprojeto no referido curso. Dessa forma, os professores participantes desta pesquisa foram egressos das duas primeiras etapas do subprojeto, a saber, os editais de 2012 e 2014. Nesse sentido, o subprojeto "Educação Física Escolar: construindo possibilidades pedagógicas a partir de uma perspectiva cultural" é desenvolvido por meio de algumas atividades entendidas como estruturantes, que o alicerçam, o organizam e o conformam. São elas: os processos de docência compartilhada; as reuniões de planejamento e avaliação do trabalho pedagógico; a produção dos memoriais de formação; as reuniões de estudo. (OLIVEIRA; CRUZ, 2016)

A docência compartilhada consiste no desenvolvimento coparticipativo da prática pedagógica, efetivando-se por meio da atuação conjunta entre bolsistas de supervisão e bolsistas de iniciação à docência nas aulas de Educação Física. Ela pode ser considerada o eixo das ações do subprojeto, em torno das quais são pensadas, articuladas e concretizadas as demais atividades estruturantes. Trata-se, também, de uma ação fundamental para o processo de iniciação à docência dos futuros professores. (OLIVEIRA; CRUZ, 2016)

O trabalho pedagógico que sustenta os processos de docência compartilhada é construído, analisado e reconstruído nas reuniões de planejamento e avaliação, que acontecem semanalmente entre grupos de bolsistas e são mediadas/orientadas pelos coordenadores de área. Nessas reuniões, as aulas são coletivamente planejadas e discutidas, a partir dos nexos estabelecidos entre a prática pedagógica e os princípios teóricos orientadores do subprojeto. (OLIVEIRA; CRUZ, 2016) 
Para ampliar e subsidiar o processo de reflexão dos bolsistas de iniciação à docência acerca das experiências que eles vivenciam na escola, as quais não se limitam à parceria com os bolsistas de supervisão no desenvolvimento das aulas de Educação Física, mas abrangem também, os diversos espaços-tempos que configuram o cotidiano e a cultuar escolar, o subprojeto recorre à produção de memoriais de formação. Esses registros representam uma escrita diária das atividades desenvolvidas nas escolas parceiras em que os bolsistas registram as concepções pessoais da prática pedagógica e da práxis escolar, expondo e analisando seus desafios, seus anseios e suas aprendizagens. (OLIVEIRA; CRUZ, 2016)

As reuniões de estudo completam o conjunto de atividades estruturantes do subprojeto. Elas acontecem periodicamente e reúnem todos os atores do Pibid - bolsistas de iniciação à docência, bolsistas de supervisão e coordenadores de área -, além de contarem com a participação de outros professores e alunos do curso de Educação Física. Esses momentos são dedicados ao estudo da perspectiva teórica em que se fundamentam as ações do subprojeto e de algumas outras referências relacionadas à Educação Física. (OLIVEIRA; CRUZ, 2016)

Além das atividades até aqui elencadas, o subprojeto em questão também procura estimular a produção de conhecimento, com base no vínculo indissociável entre docência e pesquisa, princípio que rege as ações formativas desenvolvidas pelo subprojeto. A partir da compreensão de que o ato de pesquisar é inerente ao ato de ensinar, os bolsistas são orientados a construir, ao final de cada semestre, trabalhos de cunho acadêmico-científico que sistematizem alguns dos resultados da sua experiência na escola. (OLIVEIRA; CRUZ, 2016)

Portanto, a possibilidade de vivenciar a futura profissão ainda no período de preparação é avaliada de forma muito positiva, tendo em vista que o acadêmico consegue refletir sobre sua atuação profissional através da comparação com o que é disseminado em seu ambiente de formação. Desse modo, os conhecimentos docentes adquiridos não ficam somente no imaginário, mas são assimilados e concretizados com a aplicação na prática. Assim, não se pode dissociar a teoria da prática na formação em licenciatura, no entanto percebe-se a universidade como espaço predominante teórico e a escola com espaço para atuação prática, ficando despreparado 
o aluno que vivencia apenas um âmbito desses sem o suporte do outro. (OLIVEIRA; CRUZ, 2016)

\section{Resultados e discussões: a prática pedagógica da Educação Física no início da carreira docente}

O estudo da história da educação nos permite observar que, durante muito tempo, o papel da escola esteve restrito a preparar os estudantes para sua inserção no mercado de trabalho, sendo, deste modo, subordinado à racionalidade econômica.

Diante da necessidade de repensar esse modelo de educação e de legitimar propostas que impulsionam a mudança e a formação para a cidadania, nas últimas décadas têm-se desenvolvido muitos estudos sobre a formação de professores/as, haja vista a íntima relação que a temática possui com o processo de avaliação e de reformulação do currículo reivindicadas pelos projetos de transformação da sociedade.

Em meio a esse processo, em que urge mudanças encontra-se a Educação Física, cuja constituição enquanto componente curricular se deu a partir de um paradigma respaldado na aptidão física e na biologia. Com aulas focadas, portanto, em habilidades motoras, na aprendizagem esportiva e em noções de saúde, a Educação Física vinculou-se ao interesse da cultura hegemônica e manutenção do status quo.

A análise dos dados coletados permitiu identificar os resultados alinhados em uma única perspectiva, a de que os professores participantes da pesquisa relatam que a participação no PIBID contribuiu muito ou satisfatoriamente para a inserção na educação básica e esta participação influenciou a sua opção e manutenção na atuação como profissional da educação básica.

Após o processo da coleta dos dados, obtivemos as informações iniciais como nome: Idade, sexo, ano que se formou na UNEB, tempo de participação no Pibid, em meses. Sobre o tempo de participação no programa Pibid, os participantes em média tiveram dois anos e meio, sendo o estudante desligado do programa quando atinge o último semestre do curso. 
Quadro 1: Síntese dos participantes da pesquisa

\begin{tabular}{|c|c|c|c|}
\hline Participante & Idade & Sexo & $\begin{array}{c}\text { Período de participação } \\
\text { no PIBID (em meses) }\end{array}$ \\
\hline Paula & 26 & Feminino & 24 \\
\hline Flávia & 25 & Feminino & 24 \\
\hline Kátia & 23 & Feminino & 24 \\
\hline Edson & 28 & Masculino & 30 \\
\hline Maria & 25 & Feminino & 12 \\
\hline Paulo & 24 & Masculino & 18 \\
\hline Rogério & 25 & Masculino & 24 \\
\hline Júlio & 21 & Masculino & 30 \\
\hline Sônia & 24 & Feminino & 30 \\
\hline Juliana & 26 & Feminino & 30 \\
\hline
\end{tabular}

Fonte: elaboração do autor.

A análise das entrevistas permitiu identificar algumas respostas pertinentes, como por exemplo, algumas dificuldades enfrentadas na prática docente, Maria, professora do Ensino Fundamental da rede pública de ensino. A mesma expressa à satisfação de contribuir positivamente para a formação escolar dos seus alunos, embora a realidade encontrada na rede pública de ensino seja um agravante para garantir a permanência destes profissionais, a mesma acredita na transformação pela educação.

Embora tenha dificuldades na prática pedagógica, uma vez que a escola é um espaço de situações complexas, onde a gente vai aprendendo na medida que vai ganhando experiência, o Pibid foi essencial para que eu pudesse adentrar na escola com mais segurança e com direcionamento em relação ao exercício docente. o Pibid foi uma base para a minha formação, através dele pude compreender um pouco sobre a complexidade que permeia o ambiente escolar que hoje vivencio como professora. Simplificando, o Pibid é um programa extremamente importante para que o graduando possa conhecer e reconhecer a escola e o aluno sobre seus anseios, angústias e necessidades. (Maria, 25 anos)

Sant'Anna e Marques (2015, p. 728), atentam para lógica que se insere o Pibid ao possibilitar que,

Parte da trajetória formativa do docente ocorra nas escolas públicas, inserida no cotidiano de professores e alunos e em confronto com os problemas reais que emanam da situação de ensino-aprendizagem e da gestão escolar. Dessa forma, antecipa o vínculo entre os futuros professores e a rede pública, 
esperando que boa parte destes venha a exercer o magistério nesse contexto.

Assim, é interessante que o aluno formado em uma instituição pública retribua com seu conhecimento aos indivíduos da sociedade também inseridos nesse contexto da educação. A escola pública tem seu papel formador consolidado e necessita da permanência desses professores qualificados que ela mesma ajuda a formar.

A avaliação das ações desenvolvidas no subprojeto permitiu identificar, nos resultados alcançados, a reflexão a partir de dois eixos, um referente à prática pedagógica da Educação Física nas escolas onde hoje os professores atuam e outro que concerne às ressonâncias do subprojeto no processo de formação dos ex-bolsistas. Como expressa Flávia:

O Pibid foi de suma importância pra minha formação, porém não incluir 'muito' e sim 'satisfatoriamente', pois entendendo que existem ainda outras questões da nossa formação que em conjunto com o próprio Pibid complementa esse todo e contribui nesse "muito", mas diria que o Pibid dentro de sua proposta contribuiu de forma excelente seu papel na minha formação. (Flavia, 25 anos).

Desta forma, no âmbito da prática pedagógica, destaca-se, primeiramente, a emersão de pontos de questionamento sobre as representações dominantes relacionadas às manifestações da cultura corporal, ao lugar da Educação Física na escola e às concepções curriculares da área.

Os relatos indicam uma ressignificação dos significados culturais construídos sobre as práticas corporais, este tem sido evidenciado ao longo de um trabalho pedagógico que traz à tona as representações dos alunos sobre as práticas estudadas, problematizando essas representações e procurando desvelar os marcadores sociais nelas implícitos, tais como as questões de gênero, etnia, raça, classe e religião. (NEIRA, 2011) Isso pode ser exemplificado pelas discussões desencadeadas em função da postura preconceituosa dos alunos, sobretudo a dos meninos, em relação à participação das meninas no futebol, assim como pelas reações motivadas por posições religiosas que foram manifestadas e problematizadas durante a tematização da dança, por exemplo. 
Com certeza, o Pibid foi fundamental para reforçar a minh a paixão pela licenciatura, pois ele me preparou para isso e me deu segurança para eu exercer a minha profissão. (Maria, 27 anos)

Mesmo enfrentando inúmeras dificuldades na prática pedagógica, penso que sim, porque hoje sou reflexo de um aprendizado adquirido no PIBID. Eu venho tentando desconstruir alguns preconceitos com relação a disciplina e tentando trabalhar a cultura corporal de forma crítica, pois a educação física precisa ir além da vivência pela vivência.. (Juliana, 26 anos)

Para Sant'Anna e Marques (2015, p. 729),

A implementação do Pibid nas universidades brasileiras é um processo recente e demanda estudos de avaliação de seus impactos para a formação de professores; para a melhoria da qualidade de ensino nas escolas públicas; para a valorização da carreira docente; para formulação de políticas públicas de educação; para a construção de uma gestão escolar participativa; para a integração entre ensino, pesquisa e extensão na formação do docente, entre outros.

Dessa forma, estabelece a importância de atuações como as previstas pelo Pibid para formação integral de professores. Um programa desse caráter e com essas possibilidades torna-se indispensável aos cursos de licenciaturas. Infelizmente hoje ainda não é a realidade que vivemos e professores continuam saindo das universidades mais discentes do que propriamente docentes.

Postulando por um projeto de educação que tenha compromissos com a construção de uma sociedade mais democrática, em que o processo de ensino-aprendizagem seja visto como um ato de construção e apropriação crítica e reflexiva do conhecimento, a Educação Física ainda tem dificuldade de demarcar seus objetivos e finalidades no currículo, tendo em vista que, apesar de muito se discutir as necessidades de mudanças para essa área, fortes crenças conservadoras e acríticas ainda estão nela impregnadas.

A realidade vivida na escola não é prevista pela universidade quando se tem uma formação sem prática. No entanto, não se quer dizer com isso que a universidade não desempenhe um papel fundamental na formação de professores. Ela é responsável pela sustentação científica, pela produção cultural e por todo o embasamento teórico. O que se torna incontestável é que a aproximação do âmbito universitário com o escolar - um dos objetivos do Pi- 
bid - pode fortalecer os saberes necessários para a futura atuação profissional desses acadêmicos. (DARROZ; WANNMACHER, 2015)

A inserção do programa na escola modificou a forma como a Educação Física era vista pelos alunos, professores e direção. A Educação Física passou a ser vista com mais credibilidade e atenção. (Paulo, 24 anos)

Ludke e Boing (2012) afirmam que a profissionalidade está relacionada às contribuições do trabalho. Ela põe em jogo a dimensão afetiva e talentos pessoais, de um lado, e a construção social do trabalho do professor, do outro, ao reunir os componentes de formação aos de desempenho no trabalho. Por vezes a idealização construída sobre a futura profissão não concorda com a realidade vivida no momento de atuação. Há ocasiões que por mais ampla que seja a formação teórica adquirida, ela não dará suporte para superação das dificuldades apresentadas. Cabe à experiência profissional docente conquistada na escola sustentar e transpor as barreiras que surgirão durante o trabalho.

Nota-se, então, na atualidade, que embora exista uma intensa discussão em torno da ressignificação do papel da Educação Física na escola, está ainda é vista a partir de um olhar utilitarista, de maneira em que há resistências aos discursos que propõem um componente que problematize criticamente as práticas da cultura corporal. (BERTINI JUNIOR; TASSONI, 2013) Em contrapartida, a forma pela qual a Educação Física tem sido apresentada, isto é, pautada em explicações naturalistas objetivando padrões físicos e buscando a homogeneização de alunos(as) não tem conseguido dialogar com as necessidades escolares, tampouco the assegurar no currículo.

Contudo, compreende-se a educação como responsável pela transformação e desenvolvimento social, o aprendizado é muito mais eficiente quando é obtido através da experiência por isso a necessidade e importância do professor ter consciência de estar abraçando algo que vai exigir dele uma entrega total. E nesse contexto, o subprojeto dá a noção do que o profissional docente irá encarar em sua profissão, aprendendo a lidar com as contingências diárias.

Superar esse quadro e legitimar a Educação Física em uma dimensão crítica ainda é um desafio. Trata-se de uma tarefa intensa que remete pensar, sobretudo, sobre as demandas da Educação Física na atual conjuntura escolar, pois ainda que a escola esteja sendo asfixiada 
pelos interesses do mercado, ela é constantemente requerida para contribuir com a formação humana, exercendo uma função mais formativa e menos informativa, e isto implica no desenvolvimento de uma educação que incorpore os estudantes na vida política, social e cultural de forma autônoma e crítica. Esse desafio ainda é uma barreira na atuação dos docentes em início de carreira, o que muitas vezes direcionam para uma mudança de área de atuação. Porém, a iniciação à docência por intermédio do Pibid permite uma leitura diferenciada da realidade escolar, na qual, fortalece o vínculo com este espaço de atuação, conforme a fala de Edson:

Sim, Programas como esse também servem como um divisor de águas na vida do graduando, nele o bolsista tem a oportunidade de se ver como professor e dai perceber se é esse caminho que quer percorrer. (Edson, 28 anos)

Nessa direção, para que haja realmente a ressignificação da Educação Física, faz-se necessário atentar para o processo de formação de professores, no sentido de fazer com que os professores em formação conheçam a realidade do componente curricular, reconhecendo-se nesse processo de lutas. Isso reivindica o diálogo entre o espaço acadêmico e o cotidiano escolar, que conforme Pimenta (1996) é um dos princípios fundamentais na formação docente, pois consente ao/à licenciando/a uma formação consciente e consistente, o que representa uma possibilidade de melhoria do fazer pedagógico. Essa formação apontada pela autora oportuna um consequente caminho para a legitimação da Educação Física no âmbito escolar.

\section{Considerações finais}

A realização deste estudo propõe uma discussão, para a formação profissional docente, no intuito de evidenciar a realidade de professores em início de carreira, para assim auxiliar futuros professores a enfrentar situações similares, e certamente as experiências dos colegas de trabalho poderão ser de grande utilidade no desenvolver da atividade profissional com a ampliação das investigações que se dedicam ao tema da iniciação profissional. $\mathrm{Na}$ medida em que discute algumas dimensões da profissão docente, vividas por professores iniciantes, evidenciando o Pibid como uma política de formação e iniciação à docência que tem alcançado 
grandes proporções em todo o país, os desdobramentos desse trabalho estão ligados ao desejo de produção de novas pesquisas que ressaltem a importância do Programa e defesa de sua ampliação.

Contudo, a fase inicial da profissão está diretamente relacionada à construção da identidade, ligada às primeiras experiências em sala de aula vivenciadas no subprojeto, estabelecendo relações sólidas com a comunidade escolar, revelando assim as relações entre o profissional recém-formado e o cotidiano de uma escola pública e estimulado a permanência do licenciado no exercício da carreira. O Pibid é visto de forma positiva e com fundamental importância para a formação docente dos acadêmicos que nele estão inseridos, pois através de suas articulações, o programa se torna imprescindivel para aquele que deseja se preparar para ingressar profissionalmente no espaço escolar.

Segundo Pimenta (1996), a experiência no processo de formação inicial é essencial para a formação da identidade docente, o que consequentemente irá refletir no cotidiano escolar, pois de acordo com a autora, a experiência permite ao(a) acadêmico(a), por meio de uma postura investigativa e do confronto com a realidade educacional, uma constante análise e reflexão sobre o cotidiano do trabalho docente, sobretudo, naquilo que diz respeito à área de intervenção, o que possibilita a construção de melhoria de ações pedagógicas no ambiente escolar. Ao conhecer o campo de trabalho (escola), o(a) estudante, além de conseguir manter uma relação reflexiva com os/as profissionais, pode também analisar o conjunto de significados e de práticas que dão sentido à escola, sobretudo, avaliar o seu modo de lidar com ela.

Portanto, conforme Pimenta e Lima (2004) nessa parceria, entre a universidade e a escola do Ensino Básico, o ambiente escolar representa um lugar para estudos, investigação, reflexão e intervenção, isto é, um lócus para a construção de ações consistentes e críticas, de possibilidades para que o/a licenciando/a se reconheça como sujeito capaz de promover mudanças qualitativas.

As experiências relatadas pelos bolsistas destacam o envolvimento destes com o subprojeto, assim eles puderam conhecer e refletir sobre a realidade da escola, de modo a dialogar com as discussões abordadas no subprojeto, que têm suporte teórico crítico, e que propõe a problematização da realidade e a formação de sujeitos para intervir criticamente sobre ela. Portanto, busca-se uma Educação Física que rompa com o paradigma da aptidão física e que reconheça o estudante como um ser social, político e cultural. 
Apesar de uma avaliação positiva nos resultados das ações, é importante salientar que o trabalho realizado pelo subprojeto é marcado por diversos embates e enfrentamentos, presentes na relação com os estudantes, com os professores e com os demais atores da comunidade escolar, assim como no interior da própria universidade. Afinal, contrariar a lógica que predomina na educação escolar, seja no âmbito da prática pedagógica ou no contexto das iniciativas de formação, não é uma tarefa fácil, especialmente quando se vai de encontro às representações cristalizadas, histórica e culturalmente construídas, acerca da Educação Física. Ainda assim, é possível concluir que as ações do subprojeto apontam caminhos bastante férteis para, se não ainda transformar, ao menos começar a perturbar a ordem estabelecida por essa lógica.

Ao mesmo tempo, essas ações confirmam que a escola é a unidade básica dos processos de formação e mudança; é nela que se manifestam os problemas e desafios relacionados ao ensino e onde se pode, efetivamente, construir possibilidades para enfrentá-los.

\title{
The professional initiation of teaching in Physical Education: a study with professors from the PIBID / UNEB Campus XII program
}

\begin{abstract}
This paper seeks to understand how the factors related to the institutional teaching initiation scholarship program (Pibid), developed at the State University of Bahia (UNEB) Campus XII, affect the teaching practice of teachers at the beginning of their careers. The objective is to ascertain the contributions of PIBID for the definition of the teaching professional trajectory, in order to report reflections on the permanence of the Physical Education teacher in the school context of the public school system. For that, they were interviewed egressed from the Physical Education course who were part of the Pibid/UNEB program as scholarship students of Initiation to Teaching. The target audience for the research was teachers in the early years of teaching experience. Through the analysis of the data it was possible to perceive that Pibid, qualifies the initial training of future Physical Education teachers, stimulating the permanence of the graduate in the exercise of his career. Thus, in the speeches of the graduates, Pibid is seen as of fundamental importance for the teacher education of the academics who are inserted in it. And that through its articulations, the program becomes essential for those who want to prepare themselves to enter the school space professionally. Finally, through all the study carried out and the pedagogical suggestions presented, it was possible to reflect on the influence that PIBID has on the qualification of training and the beginning of teaching activities. From this perspective, Pibid plays an important role in the constitution of the repertoire of knowledge, beliefs and actions necessary for professional teaching activities.
\end{abstract}

Keywords: Pibid. Teacher Training. Professional Performance. Physical Education. 


\title{
Iniciación docente en Educación Física: un estudio con graduados del programa PIBID / UNEB Campus XII
}

\begin{abstract}
Resumen: Este artículo busca comprender cómo los factores relacionados con el programa de becas de iniciación docente institucional (Pibid), desarrollado en el Campus XII de la Universidad Estatal de Bahía (UNEB), afectan la práctica docente de los docentes al comienzo de sus carreras. El objetivo es determinar las contribuciones de Pibid para la definición de la trayectoria profesional docente, a fin de informar reflexiones sobre la permanencia del maestro de Educación Física en el contexto escolar del sistema escolar público. Para ello, fueron entrevistados egresados del curso de Educación Física que formaban parte del programa Pibid / UNEB como estudiantes becados de Iniciación a la Enseñanza. El público objetivo de la investigación fueron los maestros en los primeros años de experiencia docente. Mediante el análisis de los datos fue posible percibir que Pibid califica la formación inicial de futuros docentes de Educación Física, estimulando la permanencia del egresado en el ejercicio de su carrera. Por lo tanto, en los discursos de los graduados, el Pibid se considera de importancia fundamental para la formación docente de los académicos que se insertan en él. Y que a través de sus articulaciones, el programa se vuelve esencial para aquellos que desean prepararse para ingresar profesionalmente al espacio escolar. Finalmente, a través de todo el estudio realizado y las sugerencias pedagógicas presentadas, fue posible reflexionar sobre la influencia que Pibid tiene en la calificación de la capacitación y el comienzo de las actividades de enseñanza. Desde esta perspectiva, Pibid juega un papel importante en la constitución del repertorio de conocimientos, creencias y acciones necesarias para las actividades de enseñanza profesional.
\end{abstract}

Palabras Clave: Pibid. Formación del profesorado. Actuación profesional. Educación Física.

\section{Referências}

BERTINI JUNIOR, Nestor; TASSONI, Elvira Cristina Martins.

A educação física, o docente e a escola: concepções e práticas pedagógicas. Revista Brasileira de Educação Física e Esporte, São Paulo, v. 27, n. 3, p. 467- 483, sept. 2013 .

BRACHT, Valter. A constituição das teorias pedagógicas da educação física. Cadernos Cedes, Campinas, v. 19, n. 48, p. 69-88, ago. 1999.

BRASIL. Lei n. 9.394/96, de 20 de dezembro 1996. Estabelece as diretrizes e bases da educação nacional. Diário Oficial da União, Brasília, DF, dez. 1996.

DARROZ, Luiz Marcelo; WANNMACHER, Clóvis Milton Duval. Aprendizagem docente no âmbito do Pibid/física: a visão dos bolsistas de iniciação à docência. Pesquisa, Educação \& Ciência, Belo Horizonte, v. 17, n. 3, p. 727-748, dez. 2015.

GOLDENBERG, Mirían; RAMOS, Marcelo Silva. A civilização das formas: o corpo como valor. In: GOLDENBERG, Mirían. (org.). Nu \& 
vestido: dez antropólogos revelam a cultura do corpo carioca. Rio de Janeiro: Record, 2002.

LUDKE, Menga; BOING, Luiz Alberto Do trabalho à formação de professores. Caderno Pesquisa, São Paulo, v. 42, n. 146, p. 428-45, 2012.

MARCELO, Carlos. Desenvolvimento profissional docente: passado e futuro. Sísifo. Revista de Ciência da Educação, Lisboa, n. 8, p. 7-22, jan./abr. 2009

NEIRA, Marcos Garcia. Educação física. São Paulo: Blucher, 2011. (Coleção A Reflexão e a Prática no Ensino, 8).

NÓVOA, Antônio. Para uma formação de professores construída dentro da profissão. Madrid, n. 350, p. 203-218, set./dez. 2009.

OLIVEIRA, Glaurea Nadia Borgues. CRUZ, Marlon Messias Santana Cruz. Educação Física escolar: construindo possibilidades pedagógicas a partir de uma perspectiva cultural. In: SILVA, Ana Lúcia da; FIGUEIREDO, Camila de Souza; SALES, Márcea Andrade. (org.) Da iniciação a docência ressignificando a pratica docente. Salvador: EdUNEB, 2016.

PIMENTA, Selma Garcia. A formação de Professores: saberes da docência e identidade do professor. Revista da Faculdade de Educação de São Paulo, v. 22, n.2. p. 72-89 jul/dez, 1996.

PIMENTA, Selma Garrido; LIMA, Maria Socorro Lucena. Estágio e docência. São Paulo:

Cortez, 2004.

ROSA, Maria Inês Petrucci et al. Formação de professores de química na perspectiva da cultura: reflexões sobre a noção de identidade profissional. In: ROSA, Maria. Inês Petrucci.; ROSSI, Adriana Vitorino. Educação química no Brasil: memórias, políticas e tendências.

Campinas: Átomo, 2008. p. 145-159.

SANT'ANNA, Paulo Afrânio; MARQUES, Luiz. Otávio Costa. PIBID Diversidade e a Formação de Educadores do Campo. Educação \&. Realidade, Porto Alegre, v. 40, n. 3, p. 725-744, Set. 2015.

TAFFAREL, Celi Zulke. ESCOBAR, Micheli Ortega. Mas, afinal, o que é Educação Física: reafirmando o marxismo contra o simplismo intelectual. Rascunho Digital, 2007. Disponível em: http://www.faced. ufba.br/rascunho_digital. Acesso em: 15 jan. 2020.

Submetido em: 18/03/2020. Aceito em: 24/06/2020 
